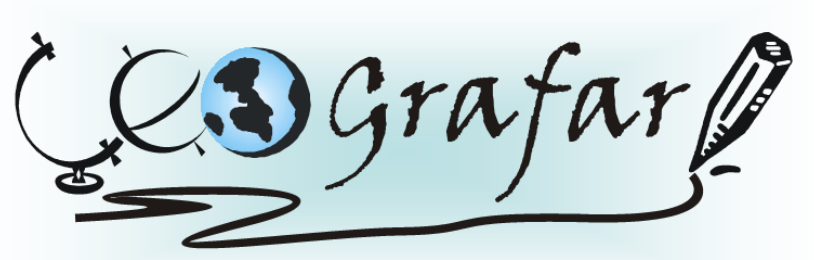

Revista Eletrônica do Programa de Pós-Graduação em Geografia - UFPR

\title{
A MODIFICAÇÃO DA PAISAGEM NO CONTEXTO HISTÓRICO DE OCUPAÇÃO DO TERRITÓRIO DO ASSENTAMENTO SÃO MANOEL - ANASTÁCIO-MS
}

\section{LANDSCAPE MODIFICATION IN THE HISTORICAL CONTEXT OF TERRITORY OCCUPATION IN THE RURAL SETTLEMENT SÃO MANOEL - ANASTÁCIO - MATO GROSSO DO SUL STATE}

\author{
Ercilia Mendes Ferreira \\ Mestranda em Geografia \\ Universidade Federal de Mato Grosso do Sul \\ Aquidauana, MS, Brasil \\ e-mail: ercilia.mendes@ufms.br \\ Cássia Julita Dresch \\ Mestranda em Geografia \\ Universidade Federal de Mato Grosso do Sul \\ Aquidauana, MS, Brasil \\ e-mail: cassiajulitadresch@gmail.com \\ Lucy Ribeiro Ayach

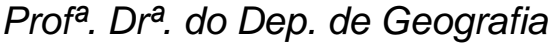 \\ Universidade Federal de Mato Grosso do Sul \\ Aquidauana, MS, Brasil \\ e-mail: luayach@terra.com.br
}

\begin{abstract}
RESUMO
O presente trabalho busca fazer uma análise espaço-temporal da evolução da paisagem a partir das contribuições obtidas na disciplina "Ecologia da Paisagem no Cerrado e Pantanal: Potencialidades e Fragilidades", ofertada no Programa de Mestrado em Geografia da Universidade Federal de Mato Grosso do Sul e tem como objetivo geral avaliar a modificação da paisagem no contexto histórico em decorrência do uso e ocupação do território pelos moradores no período de 1988 a 2015, do Assentamento Rural São Manoel, localizado no município de AnastácioMS, Micro Região Geográfica de Aquidauana, com uma extensão de aproximadamente $2.303,47 \mathrm{~km}^{2}$. O assentamento possui uma vegetação predominantemente do Cerrado, tornando-se assim importante o monitoramento dos processos de alteração neste importante bioma. Trata-se de um estudo com foco na análise ambiental, em que se busca conhecer e compreender de forma sistemática o processo de degradação ambiental ocorrido no referido assentamento. No
\end{abstract}


referencial teórico, caracteriza-se historicamente as atividades socioeconômicas e ambientais do local, assim como um recorte temporal de imagens subsidiadas com as técnicas e ferramentas do geoprocessamento: Processamento Digital de Imagens de satélite do sensor LANDSAT-5 (bandas 3, 4 e 5, ano 1988) e imagem LANDSAT8 (bandas 4, 5 e 6, ano 2015) e o trabalho de reconhecimento de campo. Foram consideradas as medidas de classes: mata, pastagem e solo exposto. Os resultados obtidos através do cruzamento e da análise de informações espacializadas indicaram que a paisagem, de 1988 a 2015, passou por momentos distintos: sua vegetação característica do Cerrado já sofria pressão antrópica antes da criação do assentamento; com a distribuição dos lotes e no decorrer do tempo em que várias tentativas sem sucesso foram realizadas com a finalidade de melhorar a qualidade de vida dos moradores, a repetição e a intensidade da ação por parte do homem em relação ao meio ambiental geraram consequências como o aumento de solos expostos. Ações como extração de madeiras para a confecção de dormentes para as linhas férreas explorada pelo antigo proprietário da área, assim como a substituição da vegetação nativa por espécie de gramíneas exóticas realizada pelos assentados em seus lotes, vêm modificando e fragilizando o bioma Cerrado, gerando indiretamente consequências que futuramente poderão afetar seriamente os recursos hídricos da referida área de estudo.

Palavras-chave: Cerrado; análise ambiental; Pantanal Sul-Mato-Grossense.

\section{ABSTRACT}

The present work makes a space-time analysis of landscape evolution after contributions obtained from the class "Lanscape Ecology in the Cerrado and Pantanal Biomes: Strengths and Weaknesses", which is offered in the Geography Masters Programme of the Federal University of Mato Grosso do Sul. The main goal is to assess the landscape changes in a historical perspective due to territory use and occupation by local residents from 1988 to 2015 in the Rural Settlement São Manoel, located in the municipality of Anastácio - Mato Grosso do Sul State, Micro Geographic Region of Aquidauana, with a total length of approximately $2.303,47 \mathrm{~km}^{2}$. The settlement has a Cerrado biome prevailing vegetation, thus becoming important to track changing processes in this relevant biome. This study focuses environmental analysis and it sought to know and comprehend in a systematic way, processes of environmental degradation within the mentioned rural settlement. The Theoretical Frame of Reference has historically characterized the environmental and socioeconomic local activities as well as a temporal cut of subsidized images with geoprocessing techniques and tools: Digital Processing of Satellite Images from sensors LANDSAT-5 (bands 3, 4 and 5, 1988) and image LANDSAT-8 (bands 4, 5 and 6,2015$)$ and field work. It was considered the following classes: forest, pasture and exposed soil. The results obtained from crossing and spatialized information analysis have indicated that landscape from 1988 to 2015 has passed through different moments: its Cerrado characteristic vegetation have already been through anthropic pressure before the settlement implementation, with plot of land distribution and throughout time, several unsuccessful attempt to improve local residents' life quality, the repetition and the human action intensity regarding environment give rise to consequences, such as increasing exposed soil. Activities such as timber harvesting in order to make crossties to railroad logged by the area previous owner, 
as well as the replacement of native vegetation by exotic grass, carried out by settled residents, are modifying and weakening the Cerrado biome, generating indirect consequences that in the future may serous affect the water resources of the mentioned study area.

Keywords: Cerrado Biome, environmental analysis, South Mato Grosso Pantanal.

\section{INTRODUÇÃO}

O maior problema enfrentado no desmatamento florestal vem principalmente da falta de planejamento e a sua realização a qualquer custo. Uma área com fins agrícolas ou mesmo de pecuária necessita da análise do uso do solo assim como de técnicas adequadas para sua preservação.

As mudanças da paisagem que aconteceram e as que ainda ocorrem são desencadeadas pela ação de agentes naturais resultado de ações ocorridas no passado distante e de agentes naturais e humanos no tempo presente. Dessa forma, verificamos que a paisagem que vemos atualmente é o resultado dos acontecimentos do passado e com certeza essa paisagem não será a mesma no futuro.

Considera-se que o modelo de reforma agrária praticado pelo INCRA vem causando sérios problemas ambientais nas áreas destinadas a assentamentos agrários, principalmente relacionados ao passivo ambiental, que representa os danos causados ao meio ambiente por atividades que estão em desacordo com a legislação ambiental, pois na maioria desses assentamentos as ações, como o mau uso dos recursos naturais, assim como a implementação de plantações e pastagens com espécies inadequadas ou técnicas incorretas podem provocar danos irreversíveis na perda da biodiversidade, a fragmentação de áreas nativas, Áreas de Preservação Permanente, Reservas Legais e a expansão de espécies exóticas.

O Passivo ambiental nos assentamentos responde por $15 \%$ do total de problemas apontados nas oficinas, refletindo assim a realidade ambiental dos PA antigos, herança de uma política que desconsiderou a dimensão ambiental da reforma agrária, deixando de cumprir a legislação vigente desde 1964. O principal ponto é a ausência ou a insuficiência de áreas de Reserva Legal averbadas e o uso inadequado destas e de Áreas de Preservação Permanentes. Em alguns casos o problema tem origem no próprio ato de criação e parcelamento do PA que não previa Reserva Legal como determina o Código Florestal Brasileiro. Em outros, a ocupação 
desordenada e a falta de informação por parte dos assentados levaram a ocupação das áreas legalmente protegidas. (INCRA, 2009, p. 20)

Desse modo, segundo Lima (2002, p.5), a paisagem pode ser considerada como a herança de uma troca de forças, "testemunhando não somente a ação dos elementos e processos naturais, mas também as interferências da presença humana". O autor faz considerações em relação às circunstâncias experienciadas, pois através delas são construídos valores e significados às suas paisagens e, levando-se em conta esses elementos, passam a criar a sua própria história de vida, surgindo assim uma territorialidade marcada, determinada pela afeição, originando o espírito de um povo e de um lugar.

Com a utilização do recurso de análise temporal da paisagem, essa técnica nos permite visualizar impactos ou modificações das áreas ocorridas ao longo do tempo.

O presente trabalho tem como objetivo avaliar a modificação da paisagem em decorrência do uso e ocupação dos lotes por moradores do Assentamento São Manoel, município de Anastácio-MS, perpassando do ano de 1988 (data que antecede a sua ocupação) a 2015, utilizando, desta forma, um recorte temporal de imagens subsidiadas com as técnicas e ferramentas do geoprocessamento. A escolha dos anos do recorte espacial desse trabalho justifica-se pelas imagens disponíveis em relação ao local de estudo. Busca-se analisar a evolução espacial ocorrida pela ocupação das famílias até o ano de 2015, realiza-se também um levantamento bibliográfico buscando identificar ações antrópicas de exploração e degradação que alteraram a área de estudo no decorrer deste período.

\section{Caracterização da área de estudo}

O Assentamento São Manoel localiza-se dentro da região fisiográfica Pantanal Sul-Mato-Grossense (Microrregião de Aquidauana), a $35 \mathrm{~km}$ da sede do município de Anastácio, na porção centro-oeste do Estado de Mato Grosso do Sul (MS), (Figura 1).

No limite da área constam os córregos denominados Criminosos, Rolador e Barreiro Vermelho, todos pertencentes à bacia hidrográfica do Rio Taquaruçu, que possui uma área de aproximadamente $2.303,47 \mathrm{~km}^{2}$, sendo sua nascente na Serra 
de Maracaju, no Município de Nioaque e Anastácio, percorrendo no sentido de sul para norte, e a sua foz localizada no Rio Aquidauana (no município de AnastácioMS). O Rio Taquaruçu abastece a cidade de Anastácio e o Rio Aquidauana a cidade de Aquidauana (ECHEVERRIA, 2008).

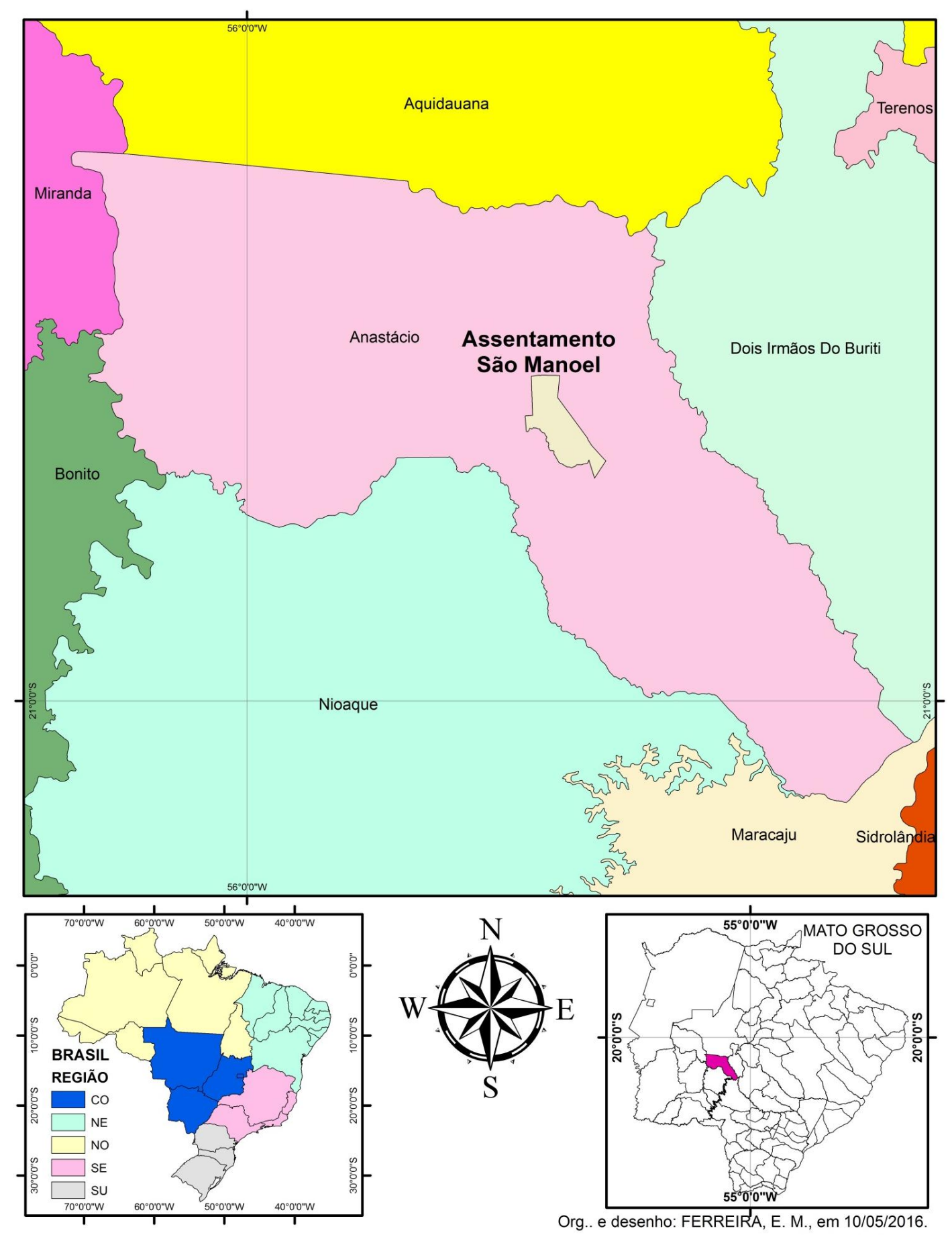

Figura 1 - Localização do Assentamento São Manoel no Município de Anastácio - MS. 
A área do assentamento ao Norte confronta-se com terras das fazendas Dona Filomena e Fazenda São Rafael; ao Sul, com córrego Criminoso e Assentamento Monjolinho; ao Leste, com terras das Fazendas Jesus Maria e Cachoeira e ao Oeste, com Fazenda São Rafael e córrego Criminoso (SILVA, 2011, p. 155).

A vegetação predominante é o Cerrado conservado em pequenos fragmentos nos lotes, ou nos espaços destinados às áreas de preservação permanente e reserva coletiva. Segundo Silva (2011), espécies de valor econômico como as aroeiras, ipês são encontradas nas áreas de reserva coletiva e alguns cedros nos fundos de vales. Destacam-se também as plantas produtoras de frutos de consumo humano que são muito utilizadas na culinária regional como o ariticum do campo, a bocaiúva, o buriti, o pequi, jatobá entre outras. O assentamento é formado por 148 lotes (maioria em média de 30 ha) distribuídos em aproximadamente 4.324,2720 hectares ou 4,32 $\mathrm{Km}^{2}$, sendo que 24 lotes constituem uma agrovila e os outros lotes restantes são individuais.

A principal atividade econômica dos assentados está baseada em regime de economia familiar. Nos lotes, existe a produção agropecuária, com destaque na produção leiteira, assim as maiores partes da exploração do solo predominam as pastagens das espécies Brachiaria Brizantha e Brachiaria decumbens (LIMA, 2010), e em alguns lotes o capim Tifton 85 (Cynodon sp), vale ressaltar que esta espécie, quando adubada e corretamente manejada, possui boa capacidade de produção e qualidade de forragem. Existe, em um número bem menor, a criação de gado bovino de corte, assim como a plantação de culturas como mandioca, milho, melancia, abóbora, maxixe e a plantação de frutas como uva, banana e mamão e algumas hortas para subsistência o fornecimento ao comércio local.

Um grande número de moradores participou de acampamentos de sem-terra. Existe uma agrovila com uma escola estadual (extensão rural da Escola Estadual Maria Correa Dias, Anastácio-MS), igrejas e mercearias com a finalidade de abastecimento da própria população.

\section{MATERIAIS E MÉTODOS}

$\mathrm{Na}$ primeira etapa desta pesquisa, realiza-se uma revisão bibliográfica em obras desenvolvidas anteriormente sobre o assentamento São Manoel, assim como 
o tema relacionado à modificação da paisagem em área rural onde ocorreu ocupação para criação de assentamentos.

Nas obras consultadas sobre a área de estudo, caracteriza-se historicamente as atividades socioeconômicas e ambientais que resultaram em ações antrópicas realizadas desde o período que antecede à criação do assentamento, pois a propriedade pertencia a Rede Ferroviária Federal (R.F.F.S/A), que no ano de 1986, foi considerada pelo INCRA como uma área totalmente improdutiva e que estava sendo explorada por uma grande carvoaria na retirada de madeira de lei, como aroreira, vinhático, chapadinha, entre outras, para fazer carvão (SILVA; ALMEIDA, 2002). Com a criação do assentamento, quando várias tentativas de plantio sem a elaboração de um projeto técnico, unido à falta de informações ou orientações técnicas acerca das características do solo, da vegetação e do clima local resultam no desmate de uma área significativa do assentamento, assim o solo sem correção e adubação correta ocasiona no fracasso desses cultivos, deixando assim algumas áreas desprotegidas e sem a adubação natural (BAMBIL, 2007). Vale ressaltar que, em outros períodos, os assentados contavam com financiamento, projeto técnico e a orientação de um agrônomo, no entanto, as falhas nos plantios também ocorrem, tornando-se assim repetitiva o uso incorreto do solo.

$\mathrm{Na}$ segunda etapa, elaboram-se mapas temáticos, utilizando as técnicas de sensoriamento remoto. Essa etapa constitui-se na elaboração dos mapas temáticos a partir da imagem de satélite do sensor LANDSAT-5 (bandas 3, 4 e 5), referente ao ano de 1988 e a imagem LANDSAT-8 (bandas 4, 5 e 6), referente ao ano de 2015, que permite a identificação e delimitação de classes do uso da terra, em relação a Matas, Pastagem e Solo Exposto, de acordo com Florenzano (2002).

$\mathrm{Na}$ terceira etapa, faz-se o levantamento de campo, no qual são realizados estudos como: registro fotográfico dos fragmentos da paisagem e interpretação preliminar das imagens de satélite sobre a vegetação.

Finalizando, realiza-se a intercepção dos dados com os mapas temáticos, permitindo assim a interpretação e avaliação das atuais condições ambientais estudadas. 


\section{RESULTADOS E DISCUSSÃO}

\section{Histórico da formação do Assentamento São Manoel}

O Estado de Mato Grosso do Sul foi criado pela Lei Complementar no. 31, de 11 de outubro de 1977, instalado a 1ำ de janeiro de 1979, abrange uma extensão territorial de $350.549 \mathrm{Km} 2$ e caracteriza-se, do ponto de vista fundiário, como um estado que apresenta alto índice de concentração de terras.

O Estado não possuía uma política que permitia o acesso à pequena propriedade e a partir de 1985 essa situação se agrava, pois, trabalhadores (arrendatários, posseiros, trabalhadores assalariados, entre outros) passam a reivindicar terras no Mato Grosso do Sul, ocasionando assim a formação de vários acampamentos. Somam-se a este movimento o retorno de famílias de brasileiros que ocupavam terras no país vizinho, o Paraguai, os denominados "brasiguaios".

Com o fortalecimento desses grupos e várias ocupações de latifúndios, o Governo do Estado busca intervir para tentar reduzir as tensões sociais. Assim, no ano de 1986, cria-se o Plano Regional de Reforma Agrária do Mato Grosso do Sul (PRRA/MS), através do Decreto n. 92.621, de 02 de maio de 1986 (BRASIL, 1986), seguindo diretrizes do Plano Nacional de Reforma Agrária (PNRA), com o objetivo de solucionar os problemas e conflitos agrários existentes através do acesso à terra, ao crédito e à assistência técnica.

O movimento social de luta pelo acesso à terra em todo o território brasileiro levou as autoridades governamentais a implantar projetos de assentamento de famílias, assim a partir da década de 1980, a implementação dos assentamentos no Brasil, resulta de uma tentativa de diminuir a violência dos conflitos sociais no campo e não transcorre de uma política de desenvolvimento voltada para o atendimento da população rural (LEITE, et. al. 2004).

No município de Anastácio, a intervenção do Estado ocorre na fazenda São Manoel de propriedade da Rede Ferroviária Federal (R.F.F.S/A), através da solicitação dos Sindicatos dos Trabalhadores Rurais da região, da CPT e do MST, para inclusão da área no 1ํ Plano Regional de Reforma Agrária (PRRA), pois a referida área servia unicamente para extração de madeiras para dormentes, assim como a presença de uma carvoaria no local. 
Em 1986, após vistoria rural realizada pelo INCRA, o imóvel é classificado como latifúndio por exploração, iniciando-se a negociação junto à empresa proprietária a aquisição do imóvel para a implantação do Projeto de Assentamento São Manoel. Devido à morosidade do andamento da aquisição até a efetivação da compra, várias invasões são realizadas até que no ano de 1993, ocorre a aquisição da área e distribuição dos lotes às famílias.

Silva e Almeida (2002) realizam uma pesquisa na qual retratam a organização social do assentamento São Manoel em 1993 e como os grupos realizaram a formação territorial dos lotes. O grupo do Movimento Sem Terra (MST), formado por famílias excedentes de outro assentamento (Assentamento Padroeira do Brasil, zona rural do município de Nioaque - MS), preferiam o sorteio dos lotes por grupos coletivos, porém esta situação gera conflitos com as famílias que desejam lotes individuais. Com esse impasse, a ocupação dos lotes é organizada em dois grupos: o grupo coletivo (MST) e o grupo individual com as famílias pertencentes ao grupo da Comissão Pastoral da Terra (CPT).

É neste contexto que se caracteriza a formação territorial do assentamento delimitado de acordo com os interesses das famílias que o constituem: forma individual e coletiva. Entre os dois grupos, o coletivo possui uma disposição territorial baseada na organização e comercialização coletiva, o que propicia maior possibilidade de geração de riqueza, determinando assim maior poder de resistência na terra como também maior solidariedade nas ações políticas reivindicatórias e os assentados individuais vivem isolados, distantes um dos outros.

Bambil (2007) através de um estudo de caso retrata o fracasso da Cooperativa de Produção Agropecuária Canudos - COPAC no Assentamento São Manoel, descreve a ocupação histórica do referido território. Em sua pesquisa, demonstra claramente que a implantação da agricultura familiar é realizada sem sucesso desde o início da distribuição das famílias em lotes, com várias experiências de plantio que são abandonadas, assim como a construção de uma represa que sofre avaria e ocorre rompimento, revelando assim o quanto as famílias encontravam-se socialmente e economicamente enfraquecidas, ocasionando consequente devastação ambiental. 
Desde a ocupação, as famílias que se organizam às margens do Córrego Criminoso, plantando roças em grupos de 4 a 5 famílias, utilizam faixas de solos férteis de fundo de vale e furnas.

Do período de acampamento (1989) até a distribuição dos lotes (1993), dois grupos se destacam: o Coletivo da Padroeira (sete famílias oriundas do município de Nioaque) e o Coletivo de Bonito (nove famílias oriundas do município de Bonito), que após um período se unificam criando o grupo Coletivo ou "grupão" que dá origem a Cooperativa COPAC.

Eles utilizam experiências de plantio de arroz e feijão nas "terras altas" com intenção comercial e nas baixadas com o solo mais fértil criam as plantações de subsistências, assim como a criação de galinhas poedeiras com características camponesas.

Com a unificação dos grupos no ano de 1993, realizam o Laboratório Organizacional do Campo, onde 188 pessoas do assentamento participam, são oferecidos vários cursos com a intenção de organização e formação da mão-de-obra com características da agricultura familiar. Ao final deste Laboratório, o grupo coletivo deixa de existir e, no ano de 1994 criam legalmente a Cooperativa COPAC. Porém, com o passar dos anos, as divergências internas entre os assentados que pertenciam a diferentes grupos partidários fazem com que várias famílias se desliguem da referida Cooperativa.

Com a legalização da Cooperativa, as famílias pertencentes têm acesso ao primeiro crédito do Programa Especial de Crédito para a Reforma Agrária PROCERA, ao qual resulta em várias ações de modificação da paisagem dentro dos lotes buscando realizar benfeitorias e melhorar a produção.

\section{Uso e ocupação do solo realizado pelas famílias}

Segundo Marcondes (2002, apud SILVA, 2011, p. 157), o assentamento São Manoel, conforme dados coletados no INCRA (1993), já possui sua cobertura vegetal original alterada antes do início do assentamento, em decorrência de frequentes queimadas e forte exploração madeireira, feita em grande parte pela Rede Ferroviária (RFFSA,) assim como pela presença de carvoarias no local. 
Relata ainda, a presença de espécies invasoras, como as exóticas mamonas (Ricinus communis), picão-preto (Bidens pilosa), caruru (Amaranthus viridis), sapé (Imperata brasiliensis) e outras.

Influenciados pela produção do Estado, o coletivo da Padroeira desenvolve a safra de algodão no período de verão entre os anos de 1991/1992, sendo exploradas as "terras altas", e as terras das baixadas são destinadas às lavouras de subsistência, em detrimento da fertilidade natural do solo.

No desmate da área do assentamento onde seria realizado o plantio, utilizase um trator de esteira alugado em troca da madeira retirada do Cerrado. A máquina utilizada não é a adequada para o tipo de atividade e o plantio é realizado manualmente sem orientação técnica de correção e adubação do solo, como consequência a produtividade esperada fica abaixo da expectativa.

Vale ressaltar que existe uma relação consideravelmente estreita entre o ciclo de nutrientes de origem da vegetação nativa e de macro e microrganismos com a fertilidade natural do solo. A manutenção desses nutrientes na superfície do solo colabora na redução da evaporação e a temperatura do solo, permitindo assim o aumento da infiltração de água e diminuição de escoamento, minimizando o desprendimento de partículas, colaborando no controle de erosões.

Solos com menos de $2 \%$ de carbono orgânico podem ser considerados erodíveis, assim o desmate, sem a prática de manejo adequado prejudica abruptamente esse ciclo natural, em que a exposição do solo a ação de elementos como a chuva e radiação solar, diminuem o potencial de produção e de espécies nativos da flora e da fauna do Cerrado.

Bambil (2007) relata que os assentados após receberem os lotes, nas primeiras tentativas de plantio não recebem orientações técnicas quanto aos aspectos do Cerrado, o que compromete as relações dos mesmos com os elementos pertencentes ao ecossistema local como: solo, vegetação, clima, entre outros; o que acarreta pouca proteção ao solo e consequentemente propicia um empobrecimento biológico, ou seja, um rompimento na estrutura do ecossistema.

Ao analisar as relações estabelecidas na paisagem ocorridas neste recorte espacial (1988 e 2015), a categoria de análise da Geografia se faz presente nesse momento onde se considera as relações sociais e naturais em um determinado espaço e a sua dinâmica. O termo paisagem considerado por Ab'Saber (2005), 
remete a ideia de herança, o autor avalia a herança dos processos fisiográficos e biológicos, assim como a herança cultural para os povos que a habitam. Nesse mesmo sentido, Nucci (2007) concorda com o pensamento de autores como Naveh e Lieberman (1984), que inserem o ser humano e sua dimensão cultural-social e econômica como parte integrante da paisagem.

Geograficamente a paisagem é a soma das inter-relações entre os processos naturais e culturais expressados por meio das unidades geoecológicas. Pode ser unicamente representada culturalmente, pois não depende exclusivamente da atitude humana para ter sua gênese, persistir ou este mesmo extinguir-se. Em contrapartida a paisagem natural é caracterizada quando há predomínio do ritmo natural e ecológico, ficando a atividade humana à margem deste sistema, porém a paisagem é dita como cultural quando em seu funcionamento geoecológico sofre interferências diretas da física e de outros fatores naturais, como o clima, geologia, geomorfologia e biota (CAVALCANTI, 2014).

Desta forma, os mapas temáticos de uso do solo gerados através do processamento digital, tendo como base a imagem LANDSAT-5 (Figura 2A), referente ao ano de 1988 e a imagem LANDSAT-8 (Figura 2B) referente ao ano de 2015 e Tabela 1 (Medidas de classes - mata, pastagem e solo exposto, conforme Florenzano, 2002), utilizados para comparar as alterações ocorridas na área entre os anos analisados resultaram em informações relacionadas ao território estudado no que tange as perdas de recursos naturais.

Tabela 1- Medidas de classe da paisagem calculada para o Assentamento São Manoel na análise temporal de 1988 e 2015.

\begin{tabular}{|c|c|c|c|c|c|}
\hline \multirow{3}{*}{\multicolumn{2}{|c|}{ Ano }} & \multicolumn{2}{|c|}{ Área total (km) } & \multicolumn{2}{|c|}{ Área em Porcentagem } \\
\hline & & 1988 & 2015 & 1988 & 2015 \\
\hline & & 31,3357000 & 14,75470 & 72,50613 & 34,1 \\
\hline \multirow{4}{*}{ gem: } & Mata: & 000 & 00000 & $\%$ & $4017 \%$ \\
\hline & \multirow[t]{2}{*}{ Pasta } & 11,4233000 & 27,45360 & 26,43181 & 63,5 \\
\hline & & 000 & 00000 & $\%$ & $2353 \%$ \\
\hline & Solo & 0,45900000 & 1,009700 & $1,06206 \%$ & 2,33 \\
\hline \multicolumn{2}{|c|}{ exposto: } & 00 & 0000 & & $63 \%$ \\
\hline \multirow{2}{*}{\multicolumn{2}{|c|}{ Total }} & 43,2180000 & 43,21800 & $100 \%$ & 100 \\
\hline & & 000 & 00000 & & $\%$ \\
\hline
\end{tabular}


No ano de 1988 (2A), a propriedade rural não se encontra ainda em processo de desapropriação. Porém já existem áreas nas quais a vegetação sofre alterações em suas características nativas em decorrência de frequentes queimadas, presença de carvoaria e a exploração de madeira realizada pela empresa proprietária do imóvel, a RFFSA.
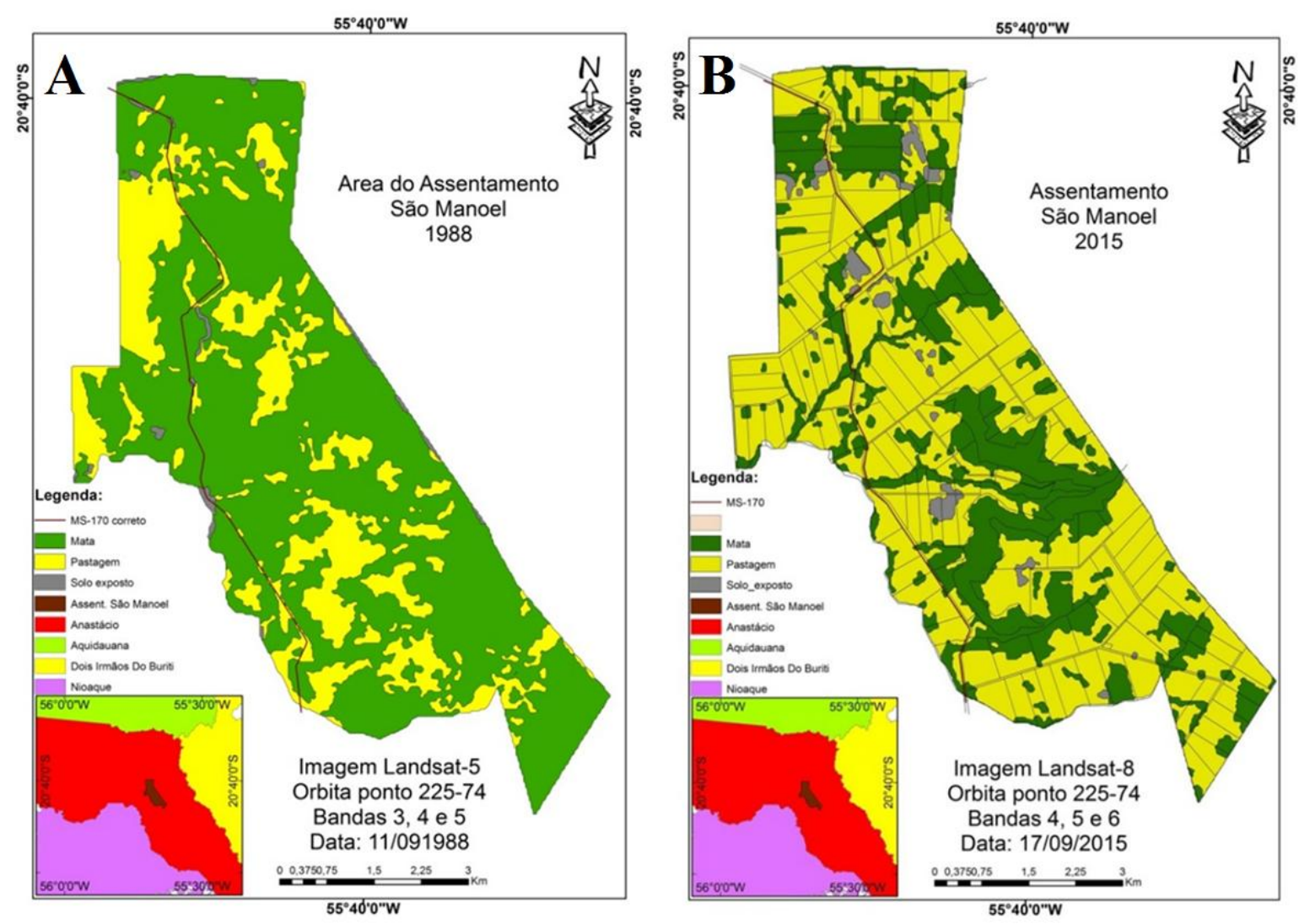

Figura 2 - A) Território do Assentamento São Manoel antes da desapropriação em 1988; B) Assentamento São Manoel - 2015 (divisão de lotes).

Considerando a área total do assentamento de 4.324,2720 ha, as medidas de classe da paisagem (Tabela 1) mostram que em 1988 a paisagem era composta por $72,50613 \%$ de mata. Nessa época, a classe pastagem compreendia aproximadamente $26,43181 \%$ do território em estudo e $1,06206 \%$ de solo exposto. No ano 2015 (figura 2B), a análise do mapeamento de uso e cobertura do solo revela que a proporção da vegetação cai para 34,14017\% de mata, acompanhada de um crescimento de áreas de pastagem para 63,52353\% e 2,3363\% de solo exposto. Acompanhando o crescimento das áreas de pastagem, a vegetação nativa vem se resumindo a pequenos fragmentos. Outro fator importante observado refere- 
se ao aumento de algumas áreas com falta de proteção do solo (Figura 3) gerando assim uma paisagem fragilizada e propensa a danos ambientais futuros, como erosões.

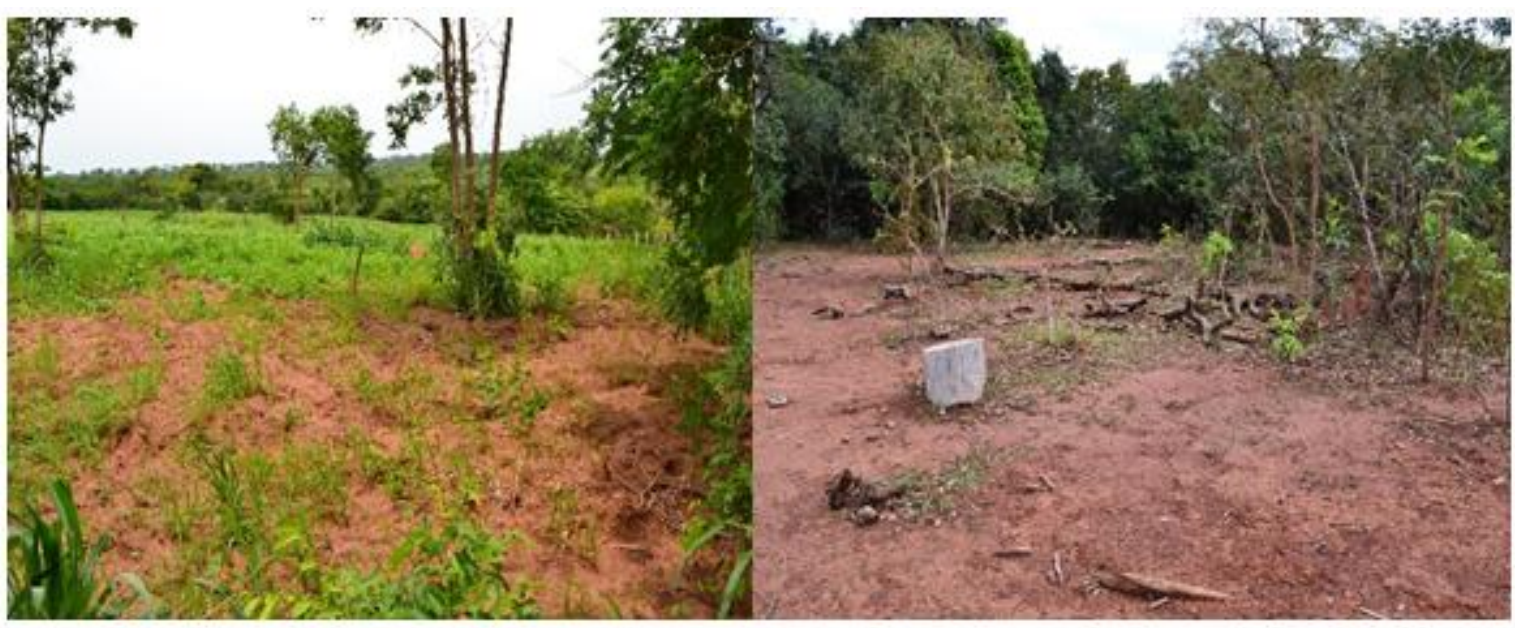

Figura 3 - Áreas de pastagem com solo exposto e áreas sem proteção Fonte: FERREIRA, E.M., 2015.

Em vinte e dois anos de ocupação, as mudanças ocorridas na paisagem são muito significativas e alarmantes, assim como vem ocorrendo com o Cerrado em toda a extensão do seu bioma no território brasileiro, ou seja, entre os anos de 1988 a 2015, 47\% da mata existente é retirada. Ocorre um declínio das matas e tais perdas contribuem para o aumento das áreas cultivadas e de solo exposto.

\begin{abstract}
Um dos biomas que mais tem estado sujeito à ocupação e à descaracterização é o Cerrado. Os fatores de indução do desenvolvimento, aliados a uma política governamental de incentivo agrícola no Cerrado estabelecida na década de 70 - e desprovida de uma proposta paralela de proteção ambiental, resultaram num processo acelerado de destruição e substituição. Ainda hoje, o Cerrado é visto como 'celeiro do mundo' ou 'área de expansão da fronteira agrícola', com estímulo oficial à sua substituição.

(...) Dentre as constantes pressões antrópicas sobre o Cerrado, destacamse: queimadas, invasões para sua ocupação com moradias e agricultura de subsistência, entrada de gado, retirada de lenha e de espécies medicinais, além da invasão biológica por espécies exóticas (PIVELLO, 2006, p. 403).
\end{abstract}

No ano de 2015 (figura 2B), o maior número de áreas preservadas de vegetação nativas na paisagem são as áreas destinadas à reserva legal e à reserva coletiva, as áreas onde encontram-se algumas redes de drenagem e também em alguns lotes que não tiveram sua mata substituída pela agropecuária. De acordo com o Instituto Nacional de Colonização e Reforma Agrária (INCRA), através da 
Instrução Normativa nำ 65, de 27/12/2010, que estabelece critérios e procedimentos para as atividades de Manejo Florestal Sustentável em Projetos de Assentamento, no Artigo Art. $2^{\circ}$, entende-se por reserva coletiva "XXX - fração ideal: área da reserva legal coletiva sob responsabilidade do assentado resultado da divisão proporcional desta pela capacidade do assentamento. "A criação da Reserva Coletiva seguiu os seguintes critérios:

\begin{abstract}
A dimensão superficial das parcelas é variável, de 15 a 50 hectares. Há uma explicação para essa variação, áreas maiores como regra, são terrenos em que parte deles existe locais de restrição para alguma prática agrícola, portanto são compensados pela extensão. Os lotes menores estão situados em área onde as condições edáficas são favoráveis ao cultivo de plantas (Figura 20). A partir dessa análise e visando à conservação de espécies do bioma Cerrado, determinou-se uma área de aproximadamente 284 hectares, denominada Reserva Coletiva, constituída de fundo de vale e elevações de parte da ramificação da Serra de Maracaju (SILVA, 2011, p. 216).
\end{abstract}

Para o Cerrado e a sua biodiversidade a erosão dos solos, a degradação da vegetação do bioma e a substituição das gramíneas nativas pelas exóticas para atender o avanço da pecuária são fortíssimas ameaças ao seu ecossistema, destacamos ainda as alterações na cobertura vegetal que afetam a hidrologia assim como a dinâmica e os estoques de carbono no ecossistema.

Ranzini e Lima (2002) consideram que a alteração da qualidade da água em Microbacias ocorre, em quase $80 \%$ em consequência da erosão do solo gerada em decorrência das diversas formas de exploração do uso da terra, com efeitos mais acentuados quanto maior a declividade do solo.

No Assentamento São Manoel, com o seu crescimento produtivo sem controle adequado geram-se, como consequências, efeitos impactantes. Destaca-se 0 atual quadro de degradação da cobertura vegetal nativa em decorrência da substituição de grande áreas da vegetação por pastagens. Este processo vem favorecendo o aumento da exposição do solo e surgimento de processos erosivos, causando assim o carreamento dos sedimentos para os cursos d'água, comprometendo sua qualidade e consequentemente desencadeando processos de assoreamento dos leitos.

Lima e Alves (2010) identificam entre as 180 famílias, 46 sendo pertencentes a unidades de produção familiar (UPF) consideradas leiteiras, nas outras 
propriedades é identificada a criação de gado solto para cria e engorda, sem aplicação de recursos tecnológicos ou investimentos financeiros. Na grande maioria dos lotes a produção agrícola, em torno de 1,5 ha em média por produtor, estava limitada a algumas culturas como milho, feijão, mandioca, hortaliças e frutas. Nas famílias pertencentes à UPF, apenas dez comercializam 0 excedente complementando a renda total da propriedade. Na grande maioria dos lotes identificam a introdução de duas espécies de pastagens, Brachiaria brizantha e Brachiaria decumbens e, em número menor o capim Tifton 85.

Vale ressaltar que a substituição das áreas por pastagens, segue modelos passados, pois alguns proprietários de lotes não possuíam rendimentos ou financiamento para o desmate e o manejo das áreas, assim o serviço dos tratores eram pagos com a troca da madeira retirada das matas.

Outra situação que vem alterando a paisagem refere-se ao desmatamento da vegetação nativa também para a formação de plantio de culturas tanto para a subsistência como para comercialização (Figura 4). Sendo assim, o assentamento encontra-se totalmente modificado, tendo apenas fragmentos que representam a reminiscências do Cerrado. Um número reduzido de produtores destaca-se no cultivo de frutíferos no Assentamento São Manoel, com plantações de mamão e inclusive parreiral de uvas, ambas com irrigação. Este tipo de produção quando acessível aos pequenos produtores proporciona aos mesmos um bom retorno econômico, assim como a adaptação ao ambiente local possibilitando melhoria no rendimento das famílias.

Porém, no caso dos lotes que utilizam as plantações com irrigação, foram projetos idealizados, implantados com orientação técnica e viabilizados economicamente por meio de projetos individuais pelos proprietários, que não pertencem a associações e nem possuem financiamento de órgãos públicos. $O$ grupo pertencente à Agrovila mantém a forma de manejo de cultivo tradicional assim como nos lotes que existem plantio de culturas para a subsistência e comercialização, são produções sem financiamento que recebem apoio da Prefeitura de Anastácio no deslocamento dos assentados para a feira semanal realizada no município. 


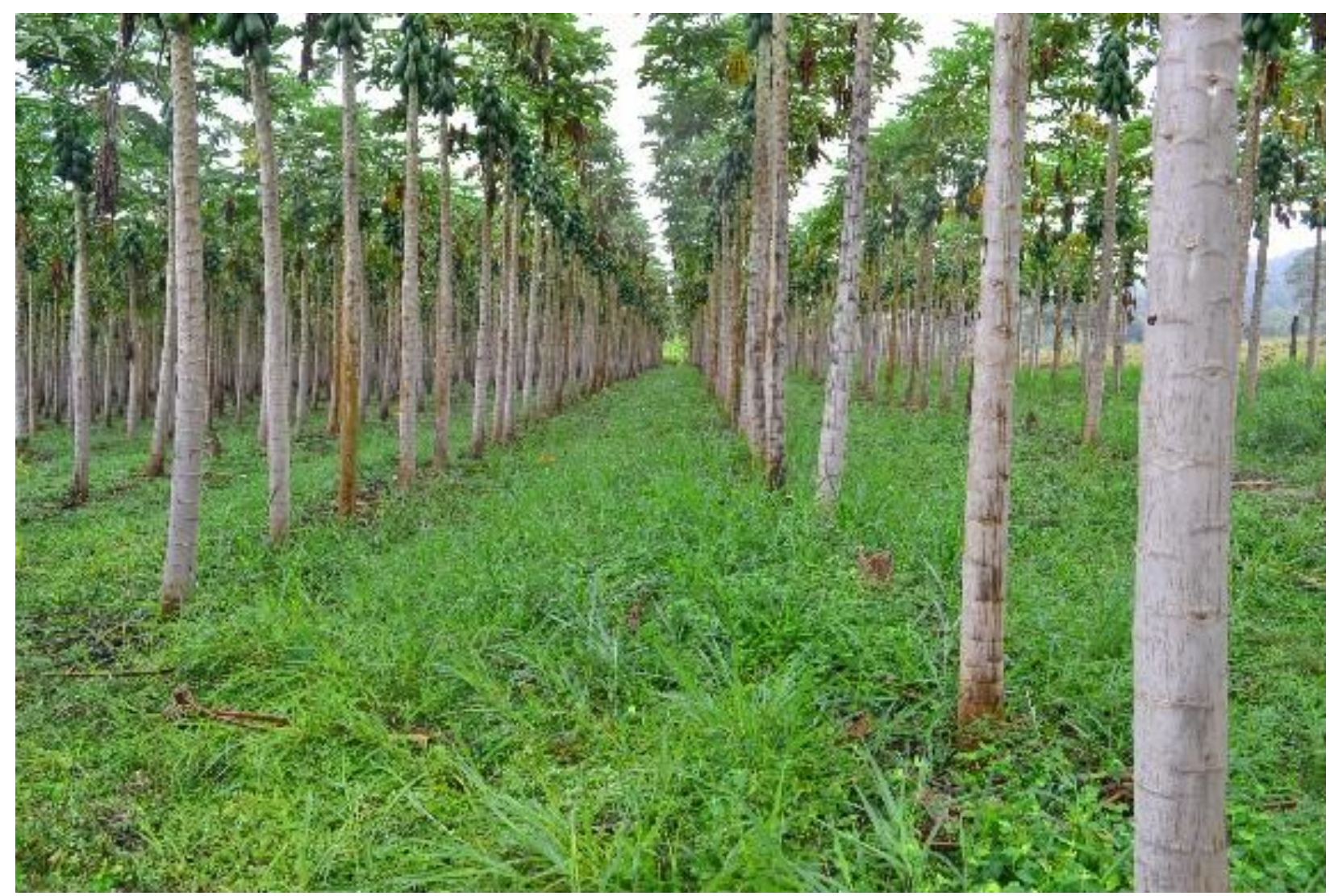

Figura 4 - Plantação de mamão para abastecer o comércio dos municípios de Aquidauana e Anastácio.

Fonte: FERREIRA, E.M., 2015

Em relação as plantações frutíferas, Ruggiero et. Al (1996) consideram necessário para a obtenção de sucesso no empreendimento frutícola o conhecimento das necessidades hídricas e nutricionais para as culturas, pois a água e os nutrientes são os fatores que mais limitam o rendimento da planta. Desta forma, torna-se claro que os cultivos realizados com planejamento ambiental possibilitam o aumento da produtividade, da qualidade dos frutos e do lucro do produtor, realidade que ocorre com um pequeno número de proprietários de lotes no assentamento São Manoel, que investiram economicamente em projetos e buscaram orientação técnica para a implantação e desenvolvimento do cultivo de frutíferos com irrigação, conseguindo uma produção que atende o comércio local da cidade de Anastácio e contribui na melhoria da renda e qualidade de vida da família.

Assim, em relação à conectividade dos fragmentos de cobertura vegetal da área estudada, verifica-se uma considerável diminuição das possibilidades de interligação entre elas (corredores ecológicos). De acordo com Alados et. al. (2004 apud BARBOSA et. al., 2006) essa alteração na distribuição espacial da cobertura 
vegetal pode ocasionar em mudanças na heterogeneidade dos padrões da paisagem, assim como na organização das interações ecológicas entre as espécies. Seguindo este mesmo pensamento, Felfili e Felfili (2001) consideram como uma das principais características do Cerrado brasileiro a heterogeneidade de espécies e habitat e que a sua perda pode refletir em diminuição de qualidade ambiental.

Forman (1983 apud VERONESE, 2009) também entende que para as populações silvestres garantirem o fluxo gênico das subpopulações (meta populações) seria de suma importância a conectividade entre os fragmentos. Da mesma forma, Turner e Metzger (1989 e 1999 apud ZANELLA, 2011) consideram que entender os padrões espaciais dos habitats resultantes dessa fragmentação torna-se de extrema importância para a conservação de populações biológicas.

Desta forma, ao estudar a realidade existente, utilizando-se de tecnologias espaciais com dados e imagens obtidas de satélite e subsidiadas com técnicas e ferramentas de geoprocessamento é possível realizar o mapeamento da cobertura vegetal e uso do solo e retratar o processo de fragmentação ou de remanescentes do bioma Cerrado existentes no Assentamento São Manoel, utilizando como contexto a apropriação histórica dos recursos naturais na formação do território pela atuação do homem, que na tentativa de dominar o meio natural, vem gerando as modificações que demonstram a paisagem ora existente, realidade que está em permanente transformação.

\section{CONSIDERAÇÕES FINAIS}

Com os resultados obtidos através dos mapas temáticos em escala temporal, é possível identificar as áreas que sofreram modificações e encontram-se com risco de comprometimento ambiental futuro. Ao realizarmos a análise de aspectos históricos sobre o uso e ocupação de áreas do cerrado possibilita-se um melhor entendimento das pressões ambientais às áreas naturais. Este processo se mostra de grande importância visto que as complexas e dinâmicas modificações nos ambientes não apenas ocorrem em seus aspectos biológicos ou naturais ocorridas no passado, mas também envolvem diversos aspectos naturais e humanos e suas interrelações. Sendo assim as modificações nos padrões da paisagem ao longo do tempo no Assentamento São Manoel estão relacionadas ao histórico de ocupação 
da área e aos aspectos culturais da população, como a repetição de práticas tradicionais oriundas das famílias, utilizando-se de técnicas rudimentares na preparação do solo, como a queimada.

Porém, considerando que o ser humano para atender as suas necessidades de sobrevivência precisa da natureza e, no entanto, o que presenciamos no período estudado é que esse processo de intervenção na natureza, que gera transformações e impactos ambientais nos ecossistemas são resultantes de alterações que estão sendo estabelecidas ao longo do tempo, onde os recursos naturais passaram em maior ou menor grau de degradação, em decorrência dos processos históricos na formação do território, no caso do assentamento, em 20 anos de existência, ocorreram muitas tentativas de criarem uma produção de subsistência e rendável aos assentados, no entanto prevaleceram as divergências políticas dos grupos, condizente com as condições físicas da área, desconhecimento de técnicas necessárias ao manejo do solo, falta de recurso financeiro assim como pouca orientação técnica que contribuíram para a sua formação atual.

Desta forma, consideramos de extrema importância o planejamento e desenvolvimento de medidas para preservar o bioma Cerrado assim como de reduzir os impactos ambientais gerados no local de estudo. Implementar ações e formas de realizar a recomposição de vegetação nativa, criar ações educativas que possam gerar conscientização da população local para que contribuam efetivamente na minimização dos efeitos negativos existentes em relação ao ecossistema.

Assim, em função do exposto quanto à área em estudo, a presente pesquisa colabora para que outros trabalhos possam surgir e acompanhar a evolução de um território e as suas dinâmicas e interações dos sistemas naturais com os sistemas agropecuários existentes na exploração familiar e, neste contexto espera-se contribuir para que estes assentados possam desenvolver mudanças e ajustes para sua própria sobrevivência.

\section{Referências}

AB'SABER, A. N. Os domínios de natureza no Brasil: potencialidades paisagísticas. 3. ed. Cotia, SP: Atelie Editorial, 2005. 
BAMBIL, A. L.. Influências da Tecnologia Moderna num Assentamento do Cerrado, município de Anastácio, MS. 2007. 83 f. Dissertação (Mestrado) Programa de Pós-Graduação em Desenvolvimento, mestrado acadêmico, Universidade Católica Dom Bosco, Campo Grande, MS, 2007.

BARBOSA, J. M.; BUENO, R. M.; ROCHA, H. H. S.; REZENDE, D. M.; COSTA, M. V. C. V.. Mudanças na paisagem e uso do solo na área rural de Sobradinho, Uberlândia, MG. Caminhos da Geografia (UFU. Online), Uberlândia, MG, v. 17, n.7, p. 187-198, 2006.

BRASIL. Decreto n 92.621, de 2 de maio de 1986. Declara a área rural do Estado de Mato Grosso do Sul como zona prioritária para efeito de execução e administração da reforma agrária, e dá outras providências. Disponível em <http://www2.camara.leg.br/legin/fed/decret/1980-1987/decreto-92621-2-maio-1986442682-publicacaooriginal-1-pe.html> Acesso em 06 fev 2016.

CAVALCANTI, Lucas Costa de Souza. Cartografia de paisagens: fundamentos. São Paulo, SP: Oficina de Textos, 2014. 95 p.

ECHEVERRIA, J. L.. Competência Fluvial do Ribeirão Taquaruçu. 2008. 100 f. Dissertação (Mestrado) - Programa de Pós-Graduação em Geografia, Universidade Federal de Mato Grosso do Sul, Campus de Aquidauana, Aquidauana, MS, 2008.

FELFILI, J. M; FELFILI, M. C. Diversidade Alfa e Beta no cerrado sensu Stricto da chapada Pratinha, Brasil. Acta Botânica Brasílica, v. 15, n. 2, p. 243-254, 2001.

FLORENZANO, T. G. Imagens de Satélites para estudos ambientais. São Paulo: Oficina de Textos, 2002.

INCRA. Instituto Nacional de Colonização e Reforma Agrária. Relatório das oficinas sobre licenciamento ambiental dos projetos de assentamento do Programa Nacional de Reforma Agrária/Ministério do Meio Ambiente. Brasília: MMA/INCRA, 2009. 116p.

INCRA. Instituto Nacional de Colonização e Reforma Agrária. Instrução normativa no 65, de 27 de dezembro de 2010. Disponível em <http://www.incra.gov.br/institucionall/legislacao--/atos-internos/instrucoes/file/262instrucao-normativa-n-65-31122010>. Acesso em: 06 fev 2016.

LEITE, S.; HEREDIA, B.; MEDEIROS, L.; PALMEIRA, M.; CINTRÃO, R. Impactos dos assentamentos: um estudo sobre o meio rural brasileiro. São Paulo: Editora UNESP, 2004. 392 p.

LIMA, J. B. M. de. Diagnóstico das Propriedades Leiteiras do Assentamento São Manoel, Anastácio MS. In: III Seminário de Agroecologia de Mato Grosso do Sul e II Encontro de Produtores Agroecológicos de MS, 2010, Corumbá, MS. Resumos, 2010. v. 5. 
LIMA, S.T. de. Reflexões a respeito da paisagem vivida, topofília e topofobia à luz dos estudos sobre experiência, percepção e interpretação ambiental. Geosul (UFSC), Florianópolis, v. 17, n.33, p. 117-141, 2002.

NUCCI, J.C. Origem e desenvolvimento da ecologia e da ecologia da paisagem. Revista Eletrônica Geografar, v. 2 (1), p.77-99, 2007.

PIVELLO, V.R. Manejo de fragmentos de cerrado: princípios para a conservação da biodiversidade, 402- 413. In: SCARIOT, A.; SOUSA SILVA, J.C. \& FELFILI, J.M (eds). Cerrado: ecologia, biodiversidade e conservação. Ministério do Meio Ambiente, 2006.

RANZINI, M; LIMA, W. de P. Comportamento hidrológico, balanço de nutrientes e perdas de solo em duas microbacias reflorestadas com Eucalyptus, no Vale do Paraíba, SP. Scentia Forestalis, n. 61. p. 144-159, jun. 2002

RUGGIERO, C.; JOSÉ, A. R. S.; VOLPE, C. A.; OlIVEIRA, J. C. de; DURIGAN, J. F.; BAUMGARTNER, J. G.; SILVA, J. R. da; NAKAMURA, K.; FERREIRA, M. E.; KAVATI, R.; PEREIRA, V. de P. Maracujá para exportação: aspectos técnicos da produção. Brasília: EMBRAPA, (Publicação técnica da FRUPEX, 19). 1996. 64 p.

SILVA, T. P. da; ALMEIDA, R. A. de. A experiência do trabalho coletivo e as transformações territoriais no assentamento São Manoel, em Anastácio/MS. Geografia, v.11, n.2, Jul/Dez. 2002

SILVA. J. F.. Modelo de Análise de Assentamento Rural: uma contribuição para gestão ambiental. 2011. 363 f. Tese (doutorado) - Programa de Pós-Graduação em Engenharia Civil, Universidade Federal de Santa Catarina, Centro Tecnológico, Florianópolis, 2011.

VERONESE, J. V. Análise de Fragmentos Florestais e proposição de corredores ecológicos com base no Código Florestal Lei 4.771/65: Aplicação na Serra do Brigadeiro - MG. 2009. 56 f. Monografia (Especialização) - Curso de Especialização em Análise Ambiental, Universidade Federal de Juiz de Fora, 2009.

ZANELLA, L. Análise da interferência antrópica na fragmentação da Mata Atlântica e Modelos de simulação da paisagem na microrregião da Serra da Mantiqueira do Estado de Minas Gerais. 2011. 116 f. Dissertação (Mestrado) Programa de Pós-Graduação em Ecologia Aplicada - Universidade Federal de Lavras, MG, 2011. 